ARCHIVO ESPAÑOL DE ARTE, LXXXV, 337

ENERO-MARZO 2012, pp. 75-94

ISSN: 0004-0428

\title{
VARIA
}

\section{UN CUADRO DE FRANCISCO PACHECO DESCONOCIDO, PERO YA PUBLICADO}

\author{
BONAVENTURA BASSEGODA \\ Universitat Autònoma de Barcelona
}

\begin{abstract}
Se presenta un cuadro firmado y fechado por Francisco Pacheco en 1629 que no ha sido recogido por la bibliografía científica, a pesar de estar ya publicado en la revista de información general La Esfera en 1930.

Palabras clave: Pintura española; siglo XVII; Francisco Pacheco; Francisco de Asís; Antonio Méndez Casal; La Esfera.
\end{abstract}

\section{A PAINTING BY FRANCISCO PACHECO, UNKNOWN YET PREVIOUSLY PUBLISHED}

A signed and dated (1629) painting by Francisco Pacheco is presented here. It has escaped the specialized bibliography in spite of having being published in the general information magazine La Esfera (1930).

Key words: Spanish painting; $17^{\text {th }}$ century; Francisco Pacheco; Francis of Assisi; Antonio Méndez Casal; La Esfera.

En el número 853 de la revista La Esfera, ilustración mundial, aparecido el 10 de mayo de 1930, se publicó a toda página una reproducción fotográfica, firmada "Cámara fto.", de un cuadro de Francisco Pacheco, que ha pasado inadvertido a todos los estudiosos recientes que nos hemos ocupado de la figura de este pintor, ilustre tratadista y famoso suegro de Velázquez (fig. 1). La pieza se reproduce con un simple pie de foto de tres líneas que dice: "Interesantísimo cuadro inédito de Francisco Pacheco (suegro de Velázquez), descubierto por el ilustre crítico de arte don Antonio Méndez Casal, durante los trabajos de tasación de los cuadros de una testamentaría. Levantada una fuerte capa de pintura dicho crítico hizo surgir la firma: 'Francisco Pacheco, 1629' (Colección del Excmo. Señor Conde de Biñasco)”.

La revista La Esfera, que se publicó en Madrid entre 1914 y 1931, era todavía en esos momentos una de las revistas más populares de la época entre las clases medias. Sus competidoras principales eran Blanco y Negro, editada desde 1891 y Nuevo Mundo, que lo fue entre 1894 y 1933. La Esfera combinaba una potente ilustración gráfica basada en fotografía de actualidad y dibujo creativo, y contaba con una excelente lista de colaboradores ${ }^{1}$. Ocasionalmente también

\footnotetext{
${ }^{1}$ Sobre La Esfera puede consultarse el trabajo de Sánchez Vigil, 2003.
} 
La Estera

IOMAS DE LA PINTURA UN CUADRO DE FRANCISCO PACHECO

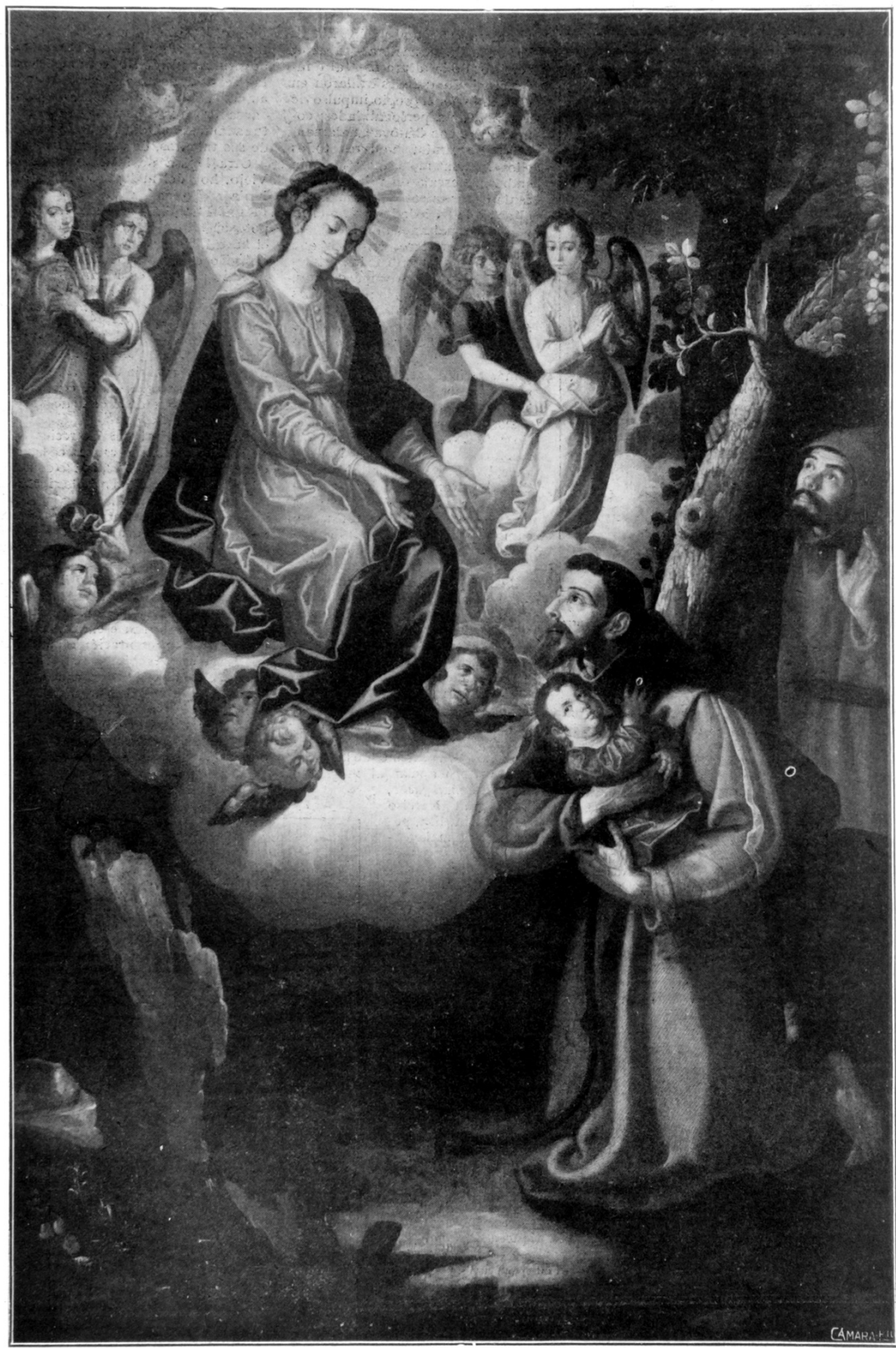

Interesantísimo cuadro inéđito, đe Francisco Pacheco (suegro de Velázquez), descubierto por el ilustre crítico de Arte don Antonio Méndez Casal, durante los trabajos de tasación de los cuadros de una testamentaria. Levantada una fuerte capa de pintura, dicho crítico hizo surgir la firma: "Francisco Pacheco, 1629". (Colección del Excmo. Señor Conde de Biñasco)

Arch. esp. arte, LXXXV, 337, ENERO-MARZO 2012, 75-94, ISSN: 0004-0428 
daba puntual noticia de descubrimientos de obras de arte antiguo, como es el caso. Antonio Méndez Casal (Monforte de Lemos, 1884-Madrid, 1940) fue elegido académico de Bellas Artes de San Fernando en febrero de 1934, pero no tomó posesión hasta septiembre de 1939. Era abogado y militar, pues llegó a ser teniente Coronel del Cuerpo Jurídico Militar. Fue colaborador muy activo de $A B C$ y de Blanco y Negro y en otras publicaciones periodísticas en donde ejerció la crítica de arte. Como estudioso de temas de arte español hay que recordar su monografía, Jenaro Pérez Villaamil, Ediciones de la Esfinge, Madrid (1923), que supuso un primer paso importante en la recuperación de este pintor romántico, y la conferencia publicada en el catálogo de la exposición, Vicente López, su vida, su obra, su tiempo, celebrada en el Centro escolar y mercantil de Valencia en 1926. Tiene también un estudio pionero sobre el pintor Rafael Tejeo en el Boletín de la Junta del Patronato del Museo Provincial de Bellas Artes de Murcia en 1925. Publicó una docena de artículos de temas muy variados, dando a conocer nuevas pinturas de Loarte, Mayno, Juárez o Vicente Giner, en la revista Arte español y en su continuadora, la Revista española de arte $^{2}$, ambas editadas por la Sociedad Española de Amigos del Arte, agrupación en la que participó activamente en la organización de tres de sus exposiciones: Retratos de Niño en España de 1925, que contiene su ensayo "El retrato de niño en España y en la pintura española", Aportación al estudio de la cultura española en las Indias de 1930, y Antecedentes coincidencias e influencias del arte de Goya celebrada en 1932, pero cuyo catálogo ilustrado no se editó hasta 1947 con el estudio fundamental de Enrique Lafuente Ferrari, "La situación y la estela del arte de Goya”. Durante la exposición, en 1932, sólo se publicó un pequeño opúsculo con la relación de las obras expuestas y un breve prólogo de Antonio Méndez Casal. Merece ser recordada también su presentación de la exposición del escultor Mateo Hernández celebrada en Madrid en 1927. La necrología que le dedicó el diario $A B C$ (14 de enero de 1940, p.16) señala que como cargos institucionales ocupaba a su fallecimiento la presidencia del Patronato del Museo de Reproducciones artísticas y la vicepresidencia del Patronato del Museo de Arte Moderno.

El Conde de Biñasco, citado en el pie de la fotografía como propietario de la pieza, sería seguramente don Alfonso Díez de Rivero y Casares, tercero de este título, nacido el 11 de diciembre de 1895 y casado con doña Dulce Nombre de María Narváez y Ulloa. Al morir sin descendencia, el título pasó a su hermano mayor, Ramón (1888-1957) y después a su hijo Alfonso Díez de Rivero y de Hoces, y de ahí a su actual titular desde 1998, Alberto Díez de Rivero y de Elzaburu. El hermano menor del actual conde me comunica amablemente por correo electrónico: "no tengo modo de saber el destino del cuadro que cita", por lo que debemos considerar la pieza en paradero desconocido.

La autoría de la tela es indudable dada su condición de obra firmada y fechada en 1629. Si no lo estuviera bastaría su proximidad con Los desposorios místicos de santa Inés, conservada en el Museo de Bellas Artes de Sevilla, firmada y fechada en 1628, para atribuirla sin reservas a Francisco Pacheco, dado que la figura de la Virgen es muy semejante en su semblante y en su pose. La escena de la aparición a santa Inés se produce en un interior doméstico, mientras que la visión de san Francisco tiene lugar en un nocturno campestre ${ }^{3}$.

A la espera que el cuadro sea dado a conocer en alguna exposición y pueda estudiarse de manera directa, dando razón de su soporte, medidas y de su estado de conservación, sólo podemos ahora apuntar un breve comentario sobre su iconografía. El episodio representado, La Virgen y el Niño que se aparecen a san Francisco, es relativamente poco frecuente en las numerosas imágenes y episodios de la vida de san Francisco de Asís. Casi siempre la escena del consuelo

\footnotetext{
2 Véase la relación de los mismos en Bibliografía del Arte en España, 1978: 401.

3 Sobre Pacheco como pintor son fundamentales los trabajos de Valdivieso-Serrera, 1985. Un estado de la cuestión puede verse en Valdivieso, 2003: 112-134.
} 
espiritual del santo al tener el Niño en brazos está asociada a otro ilustre miembro de la orden, también de gran popularidad, san Antonio de Padua. En las biografías antiguas del poverello y en las versiones de las mismas convertidas en estampas no encontramos este motivo ${ }^{4}$, siendo los episodios más habituales de apariciones sobrenaturales, la imposición de las llagas, la escena del santo confortado por el ángel músico, o la visión de la Porciúncula.

El tema de La Virgen y el Niño que se aparecen a san Francisco se difunde a lo largo del siglo XVII y seguramente nace a finales del siglo XVI como fruto de una doble contaminación. Por un lado puede verse como una simple trasposición al fundador de la orden del episodio semejante protagonizado por san Antonio de Padua, seguramente promovida por una corriente piadosa de tipo popular. Por otro, en términos visuales su composición podría derivar del motivo tradicional italiano de los cuados de altar con la Sacra conversazione, en donde vemos a la Virgen con el Niño presidiendo una reunión con otros santos, que son venerados en ese altar, capilla o iglesia. El cuadro de Ludovico Carracci, Sagrada familia con san Francisco, firmado y fechado en 1591, y ahora conservado en la Pinatoceca Civica de Cento ${ }^{5}$ o el de Sisto Badalocchio, La Virgen con el Niño con san Francisco y san Matías, de hacia 1613, conservado en la Pinacoteca Nazionale de Parma ${ }^{6}$, son dos buenos ejemplos de ese estadio iconográfico intermedio entre la Sacra Conversazione y la escena de La Virgen y el Niño que se aparecen a san Francisco ya presentada como un episodio más de la vida del santo. Este último motivo es el que se expresa ya claramente en la estampa de Francesco Villamena (1566-1624) a partir de una composición de Ferraù Fenzoni (1562-1645) ${ }^{7}$, o en la pintura de Orazio Borgianni (ca. 1578-1616) conservada en la pinacoteca de Sezze (Lazio) fechada en $1608^{8}$, o ya en el ámbito hispánico, la tela de Vicente Carducho del Museo de Budapest fechada en 1631, aunque en este caso se trata más de una visión de la Virgen Inmaculada con el Niño y no propiamente la entrega del Niño al santo por parte de la Virgen ${ }^{9}$. El motivo se consolidará y otros pintores posteriores como Antonio de Pereda, Alonso del $\mathrm{Arco}^{10}$, Carreño de Miranda ${ }^{11}$, o incluso Murillo lo incorporan a su repertorio $^{12}$. Estos precedentes italianos que acabamos de mencionar y otros posibles no son en propiedad modelos que Pacheco utilice de forma directa, pues lo que hace es adaptar a un nuevo contexto narrativo la estructura compositiva de su cuadro de los Desposorios de santa Inés, que había realizado un año antes. Cambia ahora la escenografía física del fenómeno, escena rural y nocturna, y añade la figura del compañero del santo, fray León, que es habitual en la escena de la imposición de las llagas, pero que también encontramos en el cuadro de Borgianni, de Sezze, ya citado. Sin duda, Pacheco, que era un pintor erudito y especialmente interesado por la propiedad histórica de la pintura religiosa, pasó de puntillas sobre este tema concreto y no lo menciona

\footnotetext{
${ }^{4}$ Véase la reproducción de buena parte de este amplio material en el catálogo de la exposición, L'immagine di San Francesco nella Controriforma, 1982.

5 Véase reproducido en Emiliani, [1993]: 67.

${ }^{6}$ Véase reproducido en Galleria Nazionale de Parma. Catalogo delle opere. Il Seicento, 1999: 63.

7 Véase el catálogo citado en la nota 4, n. $^{\circ} 107$, p. 175.

8 Véase el catálogo citado en la nota 4, p. 52.

9 Angulo-Pérez Sánchez, 1969: 118, lám. 114. Puede verse reproducida en color en Obras maestras del arte español. Museo de Bellas Artes de Budapest, 1996: 38.

10 Véase las dos telas de Pereda (Colección particular y Museo del Prado) y una de Alonso del Arco Madrid convento de San Pascual) en el catálogo, Don Antonio de Pereda (1611-1678) y la pintura madrileña de su tiempo, 1978, n. ${ }^{\circ} 23,36$, y 58 .

11 Tela conservada en el Museo de Guadalajara. Véase López Vizcaíno-Carreño, 2007: 191.

12 Véase Valdivieso, 2010: 500. Un dibujo anónimo de la Biblioteca Nacional de Madrid representa también este motivo y en 1927 se expuso con atribución injustificada a Murillo. Véase De Barcia, 1906: p. 74, cat. n. ${ }^{\circ}$ 353; y reproducido en, Exposición franciscana, VII centenario de la muerte de San Francisco de Asís. Catálogo general lustrado, 1927: 145 , cat. n. ${ }^{\circ} 80$, lám. XXXIX.
} 
para nada al hablar de la iconografía de san Francisco de Asís en el tercer libro de su Arte de la Pintura $^{13}$. Era consciente de su carácter no canónico, o mejor, de motivo no avalado por las fuentes biográficas antiguas relativas a la vida del santo; de ahí su elocuente silencio, mientras que en otras ocasiones es habitual en él poner como ejemplo de propiedad iconográfica a sus propias creaciones pictóricas.

La decisión precipitada de Méndez Casal por comunicar su descubrimiento en 1930 mediante una revista popular y no a través de una revista científica fue sin duda equivocada, pues más de ochenta años después de su publicación la pintura no ha sido recogida en los catálogos especializados. Confiemos en no tener que esperar otros tantos para poder conocer esta pieza en su estricta materialidad y no sólo mediante una simple reproducción fotográfica.

\section{BIBLIOGRAFÍA}

Angulo, Diego-Pérez Sánchez, Alfonso E., Historia de la Pintura española. Escuela madrileña del primer tercio del siglo XVII, Madrid, 1969.

AA.VV., Bibliografia del Arte en España. Artículos de revistas ordenados por autores, Madrid, 1978.

AA.VV., Galleria Nazionale de Parma. Catalogo delle opere. Il Seicento, Parma, 1999.

De Barcia, Ángel M., Catálogo de la colección de dibujos originales de la Biblioteca Nacional, Madrid, 1906.

Emiliani, Andrea, Ludovico Carracci, Cat. Exp., Bolonia, [1993].

Exposición franciscana, VII centenario de la muerte de San Francisco de Asís. Catálogo general ilustrado, Sociedad española de Amigos del Arte, Madrid, 1927.

Forlani Tempesti, Anna, L'immagine di San Francesco nella Controriforma, Cat. Exp., Edizioni Quasar, Roma, 1982.

López Vizcaíno, Pilar-Carreño, Ángel Mario, Juan Carreño de Miranda. Vida y obra, Oviedo, 2007.

Nyerges, Eva, Obras maestras del arte español. Museo de Bellas Artes de Budapest, Cat. Exp., Madrid, 1996.

Pacheco, Francisco, Arte de la Pintura, ed. B. Bassegoda, Madrid, 1990.

Pérez Sánchez, Alfonso E., Don Antonio de Pereda (1611-1678) y la pintura madrileña de su tiempo, Cat. Exp., Madrid, 1978.

Sánchez Vigil, Juan Miguel, La Esfera ilustración mundial (1914-1931), Madrid, 2003.

Valdivieso, Enrique y Serrera, Juan Miguel, Historia de la Pintura española. Escuela sevillana del primer tercio del siglo XVII, Madrid, 1985.

Valdivieso, Enrique, Pintura barroca sevillana, Sevilla, 2003.

Valdivieso, Enrique, Murillo. Catálogo razonado de pinturas, Madrid, 2010.

13 Pacheco, 1990: 697-700. 